\title{
The Contributions of the Psychotherapy Process Q-set to Psychotherapy Research
}

\author{
J. Stuart Ablon ${ }^{1}$, Raymond A. Levy ${ }^{1}$, Lotte Smith-Hansen ${ }^{2}$
}

This year marks the $25^{\text {th }}$ anniversary of the year that the late Enrico Jones first published his manual for the Psychotherapy Process Q-set (PQS). The manual has since been published in Jones' landmark book, Therapeutic Action (2000), and was recently revised and updated by the Massachusetts General Hospital Psychotherapy Research Program. In this article, we mark the $25^{\text {th }}$ anniversary of the PQS by reviewing both the early findings from the measure and more current research driven by those first findings.

Jones recognized that conducting horse races between different forms of psychotherapy would likely just lead to more findings of fairly equivalent outcomes. While those horse races have served the important function of providing an evidence base for a variety of different forms of psychotherapy, Jones understood that they would do little to advance our understanding of how patients improve in psychotherapy. Furthermore, he feared that Lester Luborsky's "dodo bird verdict" might lead researchers to conclude prematurely and perhaps erroneously that common factors were the only active ingredients in the treatment process.

1 Massachusetts General Hospital, Harvard Medical School, 2 Cambridge Hospital, Harvard Medical School

Corrispondence: John Stuart Ablon e-mail: sablon@thinkkids.org

While many experienced clinicians like Jones felt strongly that specific techniques in context were important predictors of treatment 
outcome, he wanted to test this hypothesis empirically. Thus, he spent the better part of a decade developing and refining a robust, sensitive, pantheoretical measure for studying psychotherapy process.

The contributions of the PQS to psychotherapy research have been of immense value. As we review below, the measure has been used to examine therapy process in studies ranging from single case designs to large randomized controlled trials, including the NIMH Treatment for Depression Collaborative Research Program (TDCRP). It has helped researchers identify key processes operating in treatment within different theoretical orientations, including psychoanalysis and psychodynamic psychotherapy, cognitive-behavioral therapy (CBT), interpersonal therapy (IPT), and control-mastery therapy (CMT). It has even helped researchers describe the unique, ideographic and idiosyncratic processes occurring within individual dyads of therapists and patients (also known as "repetitive interaction structures," "roleresponsiveness" or "enactment") which many believe lie at the very heart of therapeutic action.

\section{The Psychotherapy Process Q-Set}

The PQS itself is an instrument designed to describe psychotherapy process at the level of an individual psychotherapy session. It consists of 100 items describing therapist behaviors $(n=41)$, patient behaviors ( $\mathrm{n}=40)$, and therapist-patient interactions $(\mathrm{n}=19)$.

Examples of therapist (T) items include: $\mathrm{T}$ conveys a sense of nonjudgmental acceptance, $\mathrm{T}$ clarifies, restates or rephrases $\mathrm{P}$ 's communication, and $\mathrm{T}$ encourages $\mathrm{P}$ to try new ways of behaving with others. Examples of patient (P) items include: $\mathrm{P}$ brings up significant issues and material, $\mathrm{P}$ is tense and anxious, and $\mathrm{P}$ feels helped. Examples of interaction items include: P's treatment goals are discussed, the therapy relationship is a focus of discussion, and P's feelings or perceptions are linked to situations or behavior of the past. 
Each item is worded in neutral, descriptive language, and tied to specific behavioral and linguistic cues in order to minimize the amount of inference required by the rater. As we review below, the pantheoretical orientation of the PQS enables comparisons of therapy process between different treatment orientations.

The PQS is an ipsative measure in that independent observers rating the therapy session (from either transcripts, audiotapes, or videotapes) are instructed to sort the 100 items into categories representing items ranging from least characteristic to most characteristic of the session. In other words, the raters are required only to compare the 100 items to each other for this particular hour, not to make judgments about how the session compares to other sessions or to other standards. The instructions specify the number of items required in each of the 9 categories, and the measure thus counterbalances bias and halo effects by assuming a forced normal distribution. Different from other process measures in the field which typically examine segments of the therapeutic hour, the PQS uses an entire hour as the unit of analysis, thereby facilitating a more representative view of the session [The reader is referred to Jones, Cumming, \& Horowitz (1988) or Jones (2000) for a detailed description of the development of the PQS].

Several characteristics of the PQS speak to its strengths as a measure. It has demonstrated reliability and validity across a variety of different treatment samples including archived treatments of psychodynamic, cognitive-behavioral, client-centered, gestalt, rationalemotive and interpersonal therapies (Ablon \& Jones, 1999, 2002; Jones et al., 1988; Jones, Hall, \& Parke, 1991; Jones \& Pulos, 1993). The inter-rater reliability across all 100 PQS items has consistently yielded alpha coefficients between .83 and .89 per rater pair. Reliability analyses for individual items have also yielded acceptable to excellent values (between .50 and .95) across samples. The measure's construct and discriminant validity has also been demonstrated across studies 
(Jones et al., 1988; Jones et al., 1991; Jones, Krupnick, \& Kerig, 1987; Jones \& Pulos, 1993).

As mentioned above, Jones first developed the PQS manual 25 years ago (Jones, 1985), but later published it in his book Therapeutic Action (Jones, 2000). By now, the measure exists in both paper and electronic versions, and has been revised, updated, and translated into numerous foreign languages, including German (Albani, Ablon, Levy, Mertens, \& Kachele, 2008), Japanese (Ablon \& Goodrich, 2004), Portuguese (Serralta, Nunes, \& Ezirik, 2007), Spanish (Avila-Espada, Rampulla, Vidal, \& Herrero, 2008; Toro, Guiterrez, Avila-Espada, \& Vidal, 2008), Italian, and Norwegian.

\section{Early Research: Process Predictors of What Works for Whom}

One of the first studies conducted with the PQS verified Jones' belief that common or non-specific factors were not solely responsible for therapeutic change, but rather that specific processes would predict outcome depending on their context. Specifically, he hypothesized that distinct processes might operate differently depending on variables such as patient characteristics, therapist characteristics, presenting problem, symptom severity, and phase of treatment.

Jones, Cumming and Horowitz (1988) investigated the treatments of 40 patients with post-traumatic stress disorder (PTSD) receiving 12 sessions of psychodynamic psychotherapy in order to examine the effects of specific therapist actions and techniques. At the beginning of the treatment, patients were separated into two groups depending on the severity of their symptoms. Results showed that different PQS items were associated with therapeutic success in each group. Specifically, the authors found that specific PQS items, in interaction with patient pretreatment disturbance levels, predicted treatment outcome. In fact, successful therapies with less disturbed patients were described by 
observers using the PQS as expressively oriented, as therapists emphasized patient feelings to help him/her experience them more deeply, made connections between the therapeutic relationship and other relationships, and drew attention to patient's nonverbal behaviors. In contrast, successful therapies with more severely disturbed patients were shown to be more supportive in nature, as therapists gave more explicit advice and guidance, acted to strengthen defenses, reassured patients, and behaved in a teacher-like (didactic) manner. The diverse therapeutic strategies described with the PQS in the two groups seemed similar to what to Sifneos (1972) described as "anxiety suppressive" vs "anxiety provoking" or the "supportive" vs "expressive" techniques delineated by the Menninger Study (Wallerstein, 1986).

\section{Tracking Treatment Process Over Time}

In another early landmark study, Jones, Parke and Pulos (1992) studied the development of process over time by applying the PQS to another sample of 30 patients with a range of neurotic disorders who received 16 sessions of short-term psychodynamic treatment in a naturalistic setting. The PQS items rated most characteristic of the treatments confirmed the importance of techniques traditionally considered integral to brief psychodynamic treatments, including transference and defense interpretations, the importance of the therapy relationship, and reformulation of patients' in-session behavior. The findings also suggested that these treatments were characterized by a gradual shift from an external, reality-oriented construction of personal difficulties to an emphasis on inner experience and on the relationship with the therapist.

In identifying which PQS items were associated with outcome, the authors found that the items associated with positive outcomes 
included: $\mathrm{P}$ achieves a new understanding or insight, $\mathrm{P}$ is introspective, $P$ readily explains inner thoughts and feelings, $P$ 's aspirations or ambitions are topics of discussion, and $\mathrm{P}$ feels helped. Negative correlates of outcome included $\mathrm{P}$ resists examining thoughts, reactions, and motives, and $\mathrm{P}$ is controlling.

\section{Comparing Process in Different Types of Treatment}

Jones and Pulos (1993) then used the PQS to compare the process in the aforementioned sample of 30 patients receiving 16 sessions of psychodynamic treatment to a sample of 32 patients receiving 16 session CBT. They found that the two treatments were similar in terms of important patient characteristics, since out of the 38 PQS items not distinguishing the two treatments, as many as 26 were descriptive of patient attitudes and emotional states, e.g., anxiety, guilt, inadequacy, depression, degree of trust in $\mathrm{T}$, and sense of feeling understood by $\mathrm{T}$.

In line with the authors' hypothesis, important differences distinguished the two treatments in terms of therapist stance and technique however. The techniques employed by psychodynamic clinicians were consistent with that orientation's theoretical frame, and included evocation of affect, bringing troublesome feelings into awareness, integrating current difficulties with previous life experiences, and using the therapist-patient relationship as a change agent. Different techniques characterized the cognitive-behavioral therapies, including controlling negative affect through the use of intellect, vigorous encouragement, and support and reassurance.

Factor Analysis of PQS Items: Associations with Outcome 
In addition to producing the above findings, the study by Jones and Pulos (1993) represented an important methodological advance through the use of factor analysis to identify underlying factors across the two treatments.

Using a principal components analysis, the authors found four conceptually interpretable factors, including 1) Psychodynamic Technique (e.g., $\mathrm{T}$ is neutral, $\mathrm{T}$ interprets warded-off or unconscious wishes, feelings, or ideas), 2) Cognitive-Behavioral Technique (e.g., T actively exerts control over the interaction, there is discussion of specific activities or tasks for $\mathrm{P}$ to attempt outside of session), 3) Patient Resistance (e.g., $\mathrm{P}$ rejects vs accepts T's comments and observations, $\mathrm{P}$ resists examining thoughts, reactions or motivations related to problems), and 4) Negative Patient Affect ( $\mathrm{P}$ feels sad or depressed, $\mathrm{P}$ feels inadequate or inferior).

To the investigators' surprise, Psychodynamic Technique was significantly correlated with four out of five measures of patient improvement in CBT (and showed a near-significant trend with outcome in the psychodynamic treatment). In contrast, Cognitive-Behavioral Technique was found to have little or no relationship with outcomes in CBT, but showed a negative association with one of four outcomes in the dynamic treatment.

The Smuggling Hypothesis: Adherence to Prototypical Treatment Processes

The finding from Jones and Pulos (1993) that psychodynamic strategies were positively correlated with therapeutic outcome across both CBT and psychodynamic treatment led to a systematic line of inquiry concerning the incidence and effect of borrowing treatment processes from one approach for use in another. 
This new line of research began when Ablon and Jones (1998) used expert ratings of PQS items to develop prototypes of ideal treatment process. Specifically, Ablon and Jones first gathered panels of experts in psychodynamic and cognitive-behavioral therapy, respectively, and asked them to use the PQS to describe the process of an ideal session that adhered to their theoretical principles. Cluster analysis was then used to determine whether the panels of experts had distinct views of therapy process. Regression scores were calculated to determine the degree to which each individual item of the PQS contributed to the experts' view of ideal therapy process. Each factor array of 100 scores represented a prototype ideal treatment process according to the experts.

As the next step, using the same dataset as Jones and Pulos (1993), Ablon and Jones (1998) correlated observer ratings of actual sessions with the prototypes to determine the degree to which the actual treatments corresponded to the ideal, prototypical process prescribed by the psychodynamic and CBT experts. Finally, to determine which processes constituted the active ingredients of the treatments, they assessed the degree to which adherence to the prototypes correlated with outcome.

Surprising results emerged again. Therapists in the psychodynamic treatments fostered processes consistent with both ideal psychodynamic and cognitive-behavioral treatment, while in contrast therapists in the CBT group fostered mostly CBT processes, and not psychodynamic processes, thus adhering more closely to prescribed techniques. These results suggest that the psychodynamic clinicians employed a more heterogeneous set of treatment strategies than their CBT colleagues.

However, results furthermore showed that adherence to the CBT prototype was associated with positive outcome for only one of the six symptom measures across the psychodynamic and CBT samples, while 
degree of adherence to the psychodynamic prototype was consistently associated with positive outcome across the two groups. This was true despite very little adherence to the psychodynamic prototype in the CBT sample. Thus, the surprising finding that psychodynamic process emerged as a positive predictor of outcome in the CBT sample was a replication of previous findings in the same sample using different methods. This study also suggested, however, that the active ingredients in a treatment do not necessarily need to be the most characteristic ones. Even minimal adherence to certain therapy processes can be robust predictors of treatment outcome.

Following these findings, Ablon and Jones (1999, 2002) conducted a replication study using data from the psychotherapy arms of the NIMH Treatment of Depression Collaborative Research Program (TDCRP), at the time a state-of-the-art controlled clinical trial for depression (Elkin, Shea, Watkins, Imber, Sotsky, Collins, Glass, Pilkonis, Leber, Docherty, Fiester, \& Parloff, 1989). Results revealed significant areas of difference in process between IPT and CBT, as well as important points of similarity in the processes of both approaches. Differences in process were consistent with the theoretical distinctions between the two orientations, and centered on the therapist's stance, activity, and technique. When prototype methodology was applied, however, it became evident that both treatments adhered equally strongly to the CBT prototype. Of note, while the CBT therapists fostered a robust CBT process to the exclusion of other processes, the IPT therapists were found to be fostering both CBT and psychodynamic process. However, adherence to the CBT prototype correlated positively with treatment outcome across both groups. In summary, these results challenged the assumption that the two treatment approaches tested in the TDCRP relied on mutually distinct interventions and techniques and that positive outcomes validated their proposed mechanisms of change. The moral of this line of research seemed to be brand names of therapy 
could be quite misleading when it comes to actual treatment processes fostered and active ingredients promoting positive change.

Other PQS Findings from the TDCRP

Building on these findings, Coombs, Coleman and Jones (2002) used the TDCRP dataset to explore the role of emotion in CBT and IPT, focusing on the therapists' stance toward patients' experience and expression of emotion. Their factor analysis revealed three key factors: Factor 1, termed Collaborative Emotional Exploration, was significantly related to positive outcome in both CBT and IPT. The PQS items on this factor included $\mathrm{P}$ is introspective, readily explores inner thoughts and feelings, $\mathrm{T}$ is sensitive to the patient's feelings, and $\mathrm{P}$ has cathartic experience. Factor 2, termed Educative/Directive Process, included Discussion centers on cognitive themes, $\mathrm{T}$ behaves in a teacher-like, didactic manner, and There is discussion of specific activities or tasks for the patient to attempt outside of the session; this factor was not related to positive outcomes. These results are especially interesting given the earlier findings by Jones and Pulos (1993) that psychodynamic treatments tend to focus more on patient emotion than CBT, and that emotional exploration was correlated with improvement on four of five outcome measures in the CBT sample.

Using the CBT and IPT archives from the TDCRP, Karlsson and Kermott (2006) investigated which PQS process factors were associated with reflective functioning (RF; Fonagy, Target, Steele, \& Steele, 1998). The authors found that the PQS items most strongly associated with RF were $\mathrm{T}$ accurately perceives the therapy process, $\mathrm{T}$ draws attention to feelings regarded as unacceptable by the patient (e.g., anger, envy, or excitement), $\mathrm{T}$ is sensitive to the patient's feelings, attuned, empathic, $\mathrm{P}$ brings up significant issues and material, $\mathrm{P}$ is committed to the work of 
therapy, and $\mathrm{P}$ achieves new understanding insight. These PQS items were in turn significantly associated with positive outcomes.

In contrast, the PQS items associated with lower levels of RF were T actively exerts control over the interaction (e.g., structuring and/or introducing new topics), $\mathrm{P}$ does not initiate topics, is passive, $\mathrm{P}$ does not feel understood by the therapist, $\mathrm{P}$ feels weary or suspicious, and $\mathrm{P}$ rejects therapist's comments and observations. These items were in turn significantly related to poorer outcomes.

Taken together, the PQS findings from the TDCRP shed important light on psychotherapy process and outcome in CBT and IPT treatments. However, they also revealed the significant limitations of controlled trials of manualized treatments when it comes to studying psychotherapy process. This realization led to the next wave of research using the PQS to study psychotherapy naturalistically. While RCTs maximize internal validity, Jones and colleagues proposed the study of naturalistic treatments as an important complement to controlled studies in an effort to study psychotherapy process from a more ecologically valid perspective.

\section{Adherence to Prototypical Treatment Processes in Naturalistic Treatments}

To complement the research from the TDCRP and other RCTs, Ablon, Levy and Katzenstein (2006) studied 17 naturalistic treatments of panic disorder by seven self-identified psychodynamic clinicians delivering treatment as usual. Using the PQS, they found that the therapists employed a large spectrum of interventions, and the treatments included process variables typically associated with CBT. In fact, adherence to the CBT prototype was stronger than adherence to the psychodynamic and IPT prototypes, despite the self-identified psychodynamic orientation of the clinicians. However, adherence to IPT 
and psychodynamic process was most associated with positive outcomes. In other words, the most predominant processes were not the active ingredients of the treatment, a replication of findings from prior studies.

The authors then went a step further by using individual Q-item analyses to isolate the specific ingredients of the treatment process that predicted positive change, coining the phrase "empirically supported change processes." Specifically, they found that emphasizing feelings in order to deepen them was the single most important predictor of outcome $(\mathrm{r}=.70)$. In fact, processes aimed at facilitating expression of the patient's negative affect, such as self-accusations, shame, and guilt, negative feelings toward the therapist, and emotions deemed unacceptable by the patient were significantly associated with positive outcomes. This replicated the findings by Coombs et al. (2002), discussed above, showing that collaborative emotional exploration was key in both CBT and IPT as delivered in the TDCRP.

Ablon \& Jones (2005) also used the PQS to compare therapy process from three different treatment settings: two psychoanalyses ( $\mathrm{n}=130$ sessions), three long-term analytic therapies (two sessions weekly; $\mathrm{n}=$ 229 sessions), and two short-term dynamic therapies ( $\mathrm{n}=122$ sessions). The authors calculated each sample's correspondence to the psychodynamic prototype, and found that the two psychoanalyses demonstrated a significantly greater correlation with the prototype, while the psychoanalytic psychotherapy treatments showed a weaker correlation and the short-term dynamic therapies an even weaker correlation. The differences between each sample were statistically significant, providing the first empirical evidence that psychoanalysis proper fosters more of an analytic process than psychodynamic psychotherapy. This study also highlighted several specific items that differentiated the psychoanalyses from the long-term psychotherapies in surprising ways, providing a potential focus for future research. 


\section{Rapid vs Slow Response to Treatment}

Another unique study using the PQS was conducted by Comninos and Greyer (2008) who compared the process of early sessions of "rapid responders" and "gradual responders." The process findings revealed that the rapid responders were better able to work with intensive feelings (e.g., guilt) in early stages of therapy. In contrast, the gradual responders had high ratings of defensiveness and externalization early in treatment, despite no differences in early working alliance, which confirms prior findings regarding the importance of focusing on affect in treatment while utilizing different treatment processes depending on patient characteristics.

\section{Single Case Studies}

While the aggregated data in studies of therapy process at the group level have contributed enormously to our understanding of process and outcome, Jones and colleagues realized that their findings are too global to pinpoint the specific active ingredients in individual treatments. In parallel with the studies reviewed above, a separate group of studies using single-case designs have used the PQS to examine similar research questions about what processes operate in treatment, how process changes over time, whether therapists adhere to prescribed technique based on theoretical orientations, and how process relates to outcome. Gottman (1973) referred to single case studies as "N-of-oneat-a-time research," emphasizing that findings from $\mathrm{N}=1$ studies are valuable in part because they can be repeated across cases, leading to an accumulation of rich knowledge about therapy process and outcome. As the reader will see below, the PQS represents an ideal instrument for such research. 
The first intensive single-case study using the PQS was conducted by Jones and Windholz (1990), who examined the 6-year psychoanalysis of Mrs. C. Mrs. C was a social worker in her late 20s who sought treatment for her lack of sexual enjoyment, inability to relax, drivenness at home and at work, and self-critical tendencies. The analysis consisted of approx. 1,100 hours over six years, and the authors selected a 10-session block of audio-recordings from each year (i.e., hours 91-100 in year 1, hours 258-267 in year 2, hours 429-438 in year 3, and so on).

In order to provide a view of the salient processes in the treatment overall, the authors first identified the PQS items that demonstrated consistently high ratings and little variability across time. Consistent with traditional psychoanalytic technique, results showed that the analyst's stance was consistently neutral, accepting, and non-defensive, and that he refrained from offering direct support, reassurance, and advice. The patient was consistently rated as anxious, tense, active in initiating dialogue, but not controlling nor demanding.

In order to examine changes in therapeutic process over time, the authors compared the process from Year 1 to Year 2, from Year 3 to Year 4, and from Year 5 to Year 6. For example, from Year 1 to 2, Mrs. C began feeling less shy and embarrassed, more trusting and secure, and less concerned about how the analyst might judge her, while the analyst's communications became more direct, clear, and evocative.

Interestingly, the authors found evidence for the emergence of a transference neurosis in the fourth year of the analysis. Q-descriptors signified a remarkable heightening of Mrs. C's resistances and symptoms, as well as an increase of disturbing affect during the analytic hours, especially defiance, guilt, and intense hostility toward the analyst. Even at this difficult point in the analysis, however, she clearly made active efforts to work constructively with the analyst's interpretations. Of note, the data from the last period of the analysis 
suggested a resolution of the transference resistances, signaled in part by the patient's greater openness about her desires, feelings, and fantasies, including sexual desires and a need for intimacy.

Over the six-year period, the authors found that Mrs. C's discourse became gradually less intellectualized and dominated by rationalization, and increasingly reflected greater access to her emotional life and a developing capacity for free association. The analyst became gradually more active in challenging the patient's understanding of an experience or an event, identifying recurrent patterns in her life experience and behavior, interpreting defenses, and emphasizing feelings the patient considered wrong, dangerous, or unacceptable.

Spence, Dahl and Jones (1993) took the investigation of Mrs. C's analysis one step further by using more sophisticated methodology time series analysis. They found that associative freedom increased over time to a significant degree, and was significantly associated with the number of interventions used by the analyst in each hour, but only in the later phases of treatment. Three interventions in particular were identified which increased associative freedom in the current session and in the next three sessions; specifically, when the analyst made an interpretation directed toward the patient's defensive style, identified a recurrent theme in the material, or discussed the patient's dreams or fantasies, Mrs. C verbalizations in response demonstrated a higher degree of freedom in her associations.

A factor analysis conducted by Ablon and Jones (2005) revealed three clusters of items reflecting recurring patterns of interaction in the analysis. The process captured by the factor Patient SelfExploration/Analyst Acceptance included Mrs. C being introspective, readily examining her thoughts and reactions, and actively bringing up material; and the analyst typically accommodated her to improve the relationship during difficult interactions. However, this interaction structure became less prevalent over time. In contrast, the factor 
termed Analyst Activity gradually became more prevalent as the analysis progressed, as evidenced by the analyst exerting gradually more control over the interaction and more frequently interpreting warded-off or unconscious wishes, feelings, and ideas.

The third recurring interaction structure identified by the factor analysis was termed Playing Stupid because the analyst frequently interpreted Mrs. C's behavior during these types of interactions as her "playing stupid." The items loading most strongly on this factor included Sexual feelings and experiences are discussed, $T$ suggests the meaning of others' behavior, and Love or romantic relationships are the topic of discussion. A close examination of these interactions revealed that Mrs. C often found herself feeling confused when talking about sexual matters; in response, the analyst typically talked more and provided longer explanations and interpretations of why she found it necessary to keep herself in a confused, muddled state of mind, related in part to a memory of a time she had to "play dumb" to hide something important she knew. Interestingly, Mrs. C repeated this dynamic by having trouble understanding the analyst's interpretations in the session.

In sum, various authors used the PQS to describe in detail the dyadspecific processes involved in the successful six-year analysis of Mrs. C, including her resistance, transference, access to deepening unconscious wishes, and eventual easing of restrictions on her self-expression.

\section{The Case of Mr. A: An Integrative Psychoanalysis}

Porcerelli, Dauphin, Ablon and Leitman (2007) examined treatment process in the five-year psychoanalysis of Mr. A. Mr. A was a married computer technician, age 50, who sought treatment for chronic anxiety and a phobia related to driving on expressways. Underlying his anxiety was hostility towards his wife, inhibitions regarding advancement at 
work, sensitivity to criticism, and conflicts over sexuality. He was diagnosed with avoidant personality disorder based on clinician ratings with the Shedler-Westen Assessment Procedure (Shedler \& Westen, 1998). Mr. A was seen 3-4 times weekly on the couch for five years, but only 20 audio-recorded sessions were available for the study (four intake sessions, three therapy sessions at each year's end, and one session at follow-up).

PQS ratings of the 15 therapy sessions showed that the treatment was consistently characterized by strong psychodynamic process, as the ratings correlated significantly with the psychodynamic prototype developed by Ablon and Jones (1998, 2002). This was exemplified by therapist behaviors such as drawing attention to feelings deemed unacceptable by the patient, interpreting warded off feelings and ideas, emphasizing feelings in order to help the patient experience them more deeply, and conveying non-judgmental acceptance. Discussion frequently focused on Mr. A's dreams and fantasies and on the therapeutic relationship, both highly reflective of psychodynamic process. Characteristic patient behaviors included bringing up significant issues and material, being committed to the work of therapy, understanding the nature of therapy, experiencing ambivalent and conflicted feelings about the therapist, and being concerned about what the therapist thought of him.

Interestingly, the process in the three sessions from Year 3 (but not in other years) also showed significant correlations with the interpersonal and cognitive-behavioral prototypes, suggesting a more integrative process at that point in treatment. Of note, at this time $\mathrm{Mr}$. A and his analyst were often discussing his rage at his wife as her health deteriorated and threatened to deplete him emotionally and financially; this focus on his current relationships likely drove the correlation with the IPT prototype. Furthermore, they often discussed Mr. A's efforts to "behave differently" in relation to his wife between 
sessions; this focus on "homework" and advice giving likely drove the correlation with the CBT prototype. In sum, Mr. A's treatment was a successful psychoanalysis with significant integrative elements.

\section{The Case of Ms M: Mutual Influence in a Therapist-Patient Dyad}

The first single-case study using time series analysis of PQS data was conducted by Jones, Ghannam, Nigg and Dyer (1993) who examined the treatment of Ms. M who was in intensive, twice-weekly psychodynamic psychotherapy with Dr. X. over a period of $2 \frac{1}{2}$ years (208 sessions). M was a divorced woman in her mid-30s who sought treatment for longstanding depression. Her current depressive episode occurred in the context of difficulties with her son, age 16, who wanted to live with his father, her ex-husband. A key historical event was the accidental drowning of her older brother (who was a rival for her parents' attention) when she was a child; as a result, she felt blamed by her mother and abandoned by her father. Dr. X's formulation was grounded in Control-Mastery Theory (CMT) which is a cognitivepsychodynamic theory emphasizing the role of pathogenic beliefs and unconscious guilt in psychopathology.

The PQS was used to rate the videotapes from every fourth session $(n=53)$, and showed that Ms. M was characteristically compliant, trusting, and undemanding. She felt understood by the therapist, and accepted the therapist's comments and observations. Dr. X was consistently responsive, affectively involved, confident, and self-assured. While supportive and didactic, she also employed traditional psychodynamic technique such as interpreting and linking current feelings and experiences to the past and identifying recurrent patterns in M's life.

The authors identified four key dimensions of the therapy process through the use of an exploratory principal components factor analysis which showed four clusters of PQS items. The first factor, Therapist 
Acceptance/Neutrality, reflected Dr. X's non-judgmental acceptance, empathy, facilitation, and neutrality. Factor 2, Therapist Interactive, captured Dr. X's more authoritative behaviors, i.e., the times when she took on a more controlling, challenging, and didactic role. The factor included items related to the patient as well; presumably in response to Dr. X's authoritative stance, M had difficulty understanding Dr. X and felt misunderstood. The third factor, Psychodynamic Technique, reflected the therapist's use of traditional techniques such as interpreting warded off feelings or ideas, emphasizing unacceptable feelings, interpreting defenses, and allowing difficulties to emerge without appeasing or accommodating the patient. Factor 4, Patient Dysphoric Affect, captured M's depression and anxiety, and her efforts to control these feelings during sessions.

Taking these findings a step further, the authors used time series analysis to explore whether the four factors were related in either unidirectional and bidirectional ways. The reader is referred to Jones et al. (1993) for a detailed description of the statistical techniques employed. In brief, time series analysis was used to test whether (a) the therapist influenced the patient, (b) the patient influenced the therapist, (c) neither influenced the other, or (d) the therapist and patient influenced each other bidirectionally. The method has been used to study mother-infant, husband-wife, as well as patient-therapist interactions.

The authors found that the processes between Dr. X and M were in fact mutual and reciprocal, challenging the conventional idea that primarily the therapist's techniques bring about change in the patient. Specifically, the authors concluded that Dr. X was more neutral, nonjudgmental, and facilitative in the beginning, and that M's depressive affect during sessions gradually 'pulled' Dr. X toward a more involved and authoritative stance; this change in process in turn predicted M's reduction in depression. These findings support the notion of role 
responsiveness' (Sandler, 1976) and the idea that certain repetitive interaction structures typically develop between therapist and patient.

In addition, it was found that change in patient dysphoric affect both predicted and was predicted by both supportive and expressive techniques. Specifically, sometimes Dr. X was more reassuring in response to M's depression and anxiety, and sometimes M became less depressed in response to Dr. X's reassurance. In addition, Dr. X's transference interpretations led to increased depression and anxiety, while M's depression level predicted how often Dr. X interpreted the transference. Presumably the patient experienced Dr X's interpretations as narcissistic injuries rather than empathic, helpful explanations of her unconscious motivation.

The use of factor analysis and time series by Jones et al. (1993) represented two important methodological advancements. Building on these, Pole and Jones (1998) used the archived sessions of M's treatment to further investigate why, contrary to conventional psychoanalytic wisdom, decreased therapist acceptance and neutrality led to symptom improvement in the patient and how exactly therapy contributed to her other improvements, such as increased awareness of unconscious guilt. They furthermore examined whether M's degree of free association (measured by word co-occurrence) and discussion of key topics (related to her mother, father, brother, and guilt) were related to treatment outcomes.

Using time series analysis, the authors found that M's associative freedom (i.e., the degree to which she spoke freely and explored intrapsychic topics in depth) increased over the course of treatment, was facilitated by Dr. X's use of psychodynamic techniques, and in turn predicted symptomatic improvement. Furthermore, $M$ became more conscious of her guilt over time and her increased capacity to freeassociate predicted her later ability to express and experience guilty feelings. Dr. X's use of psychodynamic technique also directly 
influenced M's conscious experience of guilt. The analysis of key topics showed that Dr. X demonstrated a non-neutral, challenging stance during discussion of certain topics (mother, father, and guilt), but not others (brother), actively taking the stance that $\mathrm{M}$ had a right to have had better mothering and to be a better mother to her own children without having to fear hurting her mother. In other words, Dr. X was not less accepting of $\mathrm{M}$ as a person but rather less accepting of her guilt-inducing beliefs regarding her parents. Finally, time series analysis showed that M's symptoms were ameliorated by discussion of specific key topics (mother or father) but not others (brother).

Further building on these findings in their study of Ms M's treatment, Pole, Ablon and O'Connor (2008) found that overall, the treatment significantly resembled CBT and CMT prototypes (and in fact resembled ideal CBT process more than ideal CMT process), but did not resemble the psychodynamic prototype. However, looking in more detail at the PQS items describing the therapist's and patient's behaviors as well as their interactions, it was found that Dr. X's behaviors were more adherent to ideal CMT therapist behaviors than ideal CBT and psychodynamic behaviors. Interestingly, $\mathrm{M}$ 's behaviors were more adherent to ideal CBT patient behaviors than ideal CMT and PDT behaviors. In other words, the treatment's overall resemblance to CBT was driven mostly by the patient's CBT-like behaviors. The interactions between M and Dr. X were closely adherent to both ideal CMT and ideal CBT interactions.

The authors furthermore found that Dr. X's adherence to the CBT and CMT prototypes predicted symptom improvement, while adherence to the psychodynamic prototype did not. Symptom improvement did not in turn influence adherence to any of the three prototypes. Looking in more detail at what therapist, patient, and dyadic behaviors predicted symptom reduction, the authors found that improvement was predicted by therapist adherence to ideal CMT behaviors (e.g., focusing on guilt), 
patient adherence to ideal CMT behavior (e.g., testing the limits of the therapy relationship) and psychodynamic behaviors (e.g., achieving new insight), and patient-therapist interactions consistent with ideal CBT (e.g., discussion of homework) and psychodynamic (e.g., discussion of dreams and fantasies). Of note, the patient's strong adherence to CBT behaviors was not associated with improvement.

This series of single-case studies represented an important advance beyond conventional ways of measuring adherence that tend only to examine therapist techniques, by suggesting that treatment processes are co-created by therapist and patient.

\section{The Case of Maria: Ideal Technique on a Case by Case Basis}

While Pole et al. (2008) employed a generic CMT prototype specifying general ideal CMT process, Pole, Ablon, O'Connor and Weiss (2002) used the PQS to develop case-specific CMT treatment guidelines in the case of Maria. Maria was a married woman, age 30, originally from Mexico, who had forsaken her studies in veterinary medicine to care for her children and support her husband in his professional pursuits. She sought treatment for depression related to the feeling that her life had gotten off track since she withdrew from school due to an unexpected pregnancy. The CMT formulation focused on the guilt she felt for wanting to pursue her own interests (as opposed to devoting all her time to her family), and for potentially surpassing her mother, grandmother, and other women from her culture. Each of the 16 sessions was videotaped and rated with the PQS.

At the outset, the therapist and his supervisor developed a casespecific measure of ideal CMT technique based on their formulation of the patient's particular difficulties. This was done in collaboration with the progenitor of CMT. The guidelines specified that in an ideal session, the therapist would focus on the patient's guilt; provide supportive, encouraging, and reassuring statements; interpret unconscious wishes, 
feelings, and ideas; and facilitate the patient's speech (which was especially important since she doubted her English proficiency).

The authors found that Maria's self-rated in-session affect associated with feeling ineffective and depressed fluctuated from session to session, but showed improvement over time, as did the therapeutic alliance (rated by patient, therapist, and independent observers). Session outcomes in terms of therapist helpfulness, patient response, and overall session quality (also rated by patient, therapist, and independent observers) showed a range from session to session, but improved moderately over time. Therapist-rated adherence was close to ideal CMT throughout and improved over the 16 sessions.

Furthermore, adherence to ideal CMT technique was associated with reduced ineffective and depressed affect in session and with positive patient- and observer-rated session outcomes. Adherence was more strongly correlated with positive session outcomes than was the therapeutic alliance, and even predicted outcome above and beyond the combined effects of the passage of time, the in-session affect, and the therapeutic alliance.

These findings speak clearly to the importance of developing measures of case-specific ideal technique based on theory-driven formulation of individual patients' difficulties, rather than adhering rigidly to generic techniques specified by treatment manuals (which can be associated with negative process and outcomes, as shown by Castonguay, Goldfried, Wise, Raue, \& Hayes, 1996; Henry, Strupp, Butler, Schacht, \& Binder, 1993).

The Case of Amalia X: The Private Meanings of Session 152

Amalia X was an adult German woman who sought psychoanalysis for depression with underlying self-esteem difficulties related to excessive body hair growth (hirsutism). She felt that, starting in puberty, her life had suffered severe strain related to this problem, 
resulting in significant anxiety, depression, irritability, compulsiveness, and social insecurity. She attended 517 sessions with good results.

Amalia is considered the German specimen case, and her analysis has been studied extensively. Albani, Blaser, Jacobs, Jones, Thomä, \& Kächele (2002) used the PQS to examine five therapy hours from early in treatment and five hours from the end of the treatment. The PQS items that were characteristic across these ten sessions included the analyst being empathic, neutral, accepting, and tactful, while the patient was consistently active in beginning the hour and bringing up significant issues and material, spoke of wanting to be separate, and accepted the analyst's comments and observations. The sessions were consistently characterized as having a specific focus, e.g., the patient's body image, relationships, or cognitive themes.

In comparing the early treatment process to the process at the end of treatment, the authors identified several PQS items that distinguished the two treatment phases. In the beginning, the analyst more often asked for more information, clarified, facilitated the patient's speech, and identified recurrent themes in the patient's experience; the patient had a clearer and more organized expression, felt shy and inadequate more often, and expressed shame and guilt more frequently (compared to the end of treatment). At the end of treatment, the analyst reformulated the patient's behavior less, had a reduced focused on the patient's feelings of guilt, and was less active in exerting control of sessions; the patient was more controlling, provocative, resistant to examining thoughts and feelings, and more able to express anger (compared to the beginning of treatment).

Neither the beginning nor the ending closely resembled the psychoanalytic prototype, suggesting that the psychoanalytic work was just beginning or coming to a close. These findings indicate that psychoanalytic treatments are more varied than adherents of theoretical 
purity suggest and that treatments do not necessarily conform to theoretical prototypes, a replication of earlier findings.

At the same time, session 152 of Amalia's treatment has in fact been identified as a prime example of modern psychoanalytic technique. In this session, Amalia brings up an important dream, and the analyst helps her explore its unconscious meanings by drawing no sharp distinctions between fantasy and reality. The most characteristic PQS items for this session included P's dreams and fantasies are discussed; T's remarks are aimed at facilitating speech; $\mathrm{T}$ interprets warded-off or unconscious wishes, feelings, or ideas; and the analytic relationship is a focus of discussion. The least characteristic items included $\mathrm{T}$ acts to strengthen defenses; $\mathrm{P}$ does not feel understood; $\mathrm{P}$ does not initiate topics, is passive; and real vs fantasized meanings of experience are actively differentiated.

As described by Levy, Ablon, Ackerman and Seybert (2008), session 152 was particularly difficult to rate with the PQS, in part because of the complex dialogue, personal associations, and intimate exchange between analyst and patient. The raters indeed had the experience of being invited into "a very private world of dyadic meaning."

The PQS items most difficult to rate for session 152 included item 42 ( $\mathrm{P}$ rejects rather than accepts T's comments and observations) in part because Amalia at times first resisted the analyst's interpretations, but then shifted focus to deepen the conversation. Another difficult item was item 58 (P resists examining thoughts, reactions, or motivations) mainly because she readily explored parts of the transference, but resisted expressing her sexual thoughts and feelings. In fact, item 11 (sexual feelings or experiences are discussed) was difficult to rate in part because Amalia made several references to sexual content without direct mention, and in fact appeared to actively resist deeper discussion of it. 
A final example was item 12 (silences occur during the hour). This item was difficult to rate because the session contained several long silences, including one reflecting significant resistance prior to Amalia's changing the subject. However, the raters felt that the silences did not change the flow of the session in major ways, as the session had a vitality and productive energy to it overall. The silences seemed to reflect shifts in focus, rather than ruptures in the relationship or suppressed aggression, so the raters rated them as less salient. In sum, while some items were difficult to rate, the PQS allowed the researchers to capture even the private meanings and unique processes of session 152 of Amalia's analysis.

\section{The Case of Beth}

Beth was a woman in her mid-20s who sought treatment soon after choosing to leave graduate school in the physical sciences due to intense competition and performance pressures. She felt lost and stuck in her professional pursuits, and had applied for no jobs since leaving graduate school. She broke off her romantic relationship with her girlfriend of many years soon after leaving graduate school, but continued to live with her. Beth was in twice-weekly psychotherapy for approximately 15 months with Dr. A, a psychologist of a psychodynamic orientation who was asked to conduct the treatment as she would if seeing Beth in private practice.

Katzenstein (2007) examined process and outcome in Beth's treatment using the PQS ratings from every other hour $(\mathrm{n}=61)$, derived from the transcripts of the videotaped sessions. The treatment process was found to adhere most closely to the psychodynamic prototype $(\mathrm{r}=$ $.43)$ and the cognitive-behavioral prototype $(r=.38)$ with no statistically significant difference in adherence between the two. The process correlated significantly less with the interpersonal prototype $(r=.20)$. 
However, adherence to psychodynamic process was the only significant predictor of symptom level and symptom change.

A principal components factor analysis revealed two factors underlying the PQS items. Factor 1 was labeled Patient's Affective and Cognitive Distancing and described a stance frequently taken by Beth during sessions. Specifically, she had a strong tendency to distance herself from her own experience, as exemplified by PQS items such as $\mathrm{P}$ is controlling, $\mathrm{P}$ is anxious and tense, $\mathrm{P}$ discusses experiences as if distant from feelings, and $\mathrm{P}$ resists examining thoughts, reactions, or motivations. The item with the strongest negative factor loading was $\mathrm{P}$ is introspective and readily explores inner thoughts and feelings.

Factor 2 was labeled Therapist Cutting Through to Affect, and described Dr. A's efforts to help Beth focus on and talk about her inner experience. This stance was exemplified by PQS items such as T emphasizes the patient's feelings to help him/her experience them more deeply, T's remarks are aimed at facilitating speech, and $\mathrm{T}$ asks for more information or elaboration.

Time series analysis showed that Beth's level of symptom distress 1) resulted in more frequent distancing and disengaging from her thoughts and feelings, and 2) led Dr. A to focus more on affect to help her access her thoughts and feelings more deeply. These efforts in turn predicted a reduction in Beth's level of symptom distress in a reciprocal manner.

Interestingly, in the exit interview with an independent clinician, Beth spoke eloquently about these processes when asked what made the treatment effective: "My therapist had me talk in very concrete terms and get in touch with a lot of my feelings... I was able to talk about those things instead of spending all my energy staying away from it... She made me aware that I talked about my feelings in abstract ways... I think this was a big part of what was helpful to me about our therapy and what helped me feel better." 
Taken together, the single-case studies reviewed above provide a rich description of process and outcome in each dyad as an important complement to the aggregated data in studies at the group level. Most importantly, single-case studies have allowed for an ideographic examination of the particular processes at play in individual treatments, greatly facilitated by prototype methodology, factor analysis, and time series analysis.

To review, these ideographic processes included 1) Mrs. C's development and resolution of a transference neurosis, and her tendency to "play stupid" in certain sessions, 2) the use of interpersonal and cognitive-behavioral techniques during Year 3 of Mr. A's analysis (but not during other years), 3) the process by which M's depressive affect gradually pulled Dr. X away from his original neutral position towards a more involved and authoritative posture, which in turn predicted improvement in M's depression, and the importance of Dr. X's gradual change to become more challenging of M's guilt-inducing beliefs regarding her parents, 4) the usefulness of developing and adhering to case-specific ideal technique, driven by a CMT formulation, by Maria's therapist, 5) the 'private world of dyadic meaning' between Amalia and her analyst, and 6) Beth's tendency to distance herself from her feelings, Dr. A's efforts to help her access them, and the resulting improvement in symptoms. Of note, in several of these studies, researchers identified how these ideographic, idiosyncratic processes between patient and therapist (often called "enactments," "roleresponsiveness" or "repetitive interaction structures;" Jones, 2000) relate to positive treatment outcome.

\section{The PQS in Relation to Other Measures of Process}

While the PQS has primarily been used to examine process and outcome in psychotherapy studies, the instrument has also been found 
to be helpful in elucidating key constructs such as the therapeutic alliance and countertransference.

Price and Jones (1998) examined the PQS in relation to alliance using the archived sample of 30 brief psychodynamic treatments from Jones, Parke and Pulos (1992). They found that 19 PQS items correlated significantly with alliance as measured by the CALPAS (Marmar, Gaston, Gallagher, \& Thompson, 1989), including $\mathrm{P}$ feels helped, $\mathrm{P}$ conveys positive expectations about therapy, $\mathrm{P}$ achieves a new understanding or insight, $\mathrm{P}$ is committed to the work of therapy, $\mathrm{P}$ is introspective and readily explores inner thoughts and feelings, and $\mathrm{P}$ understands the nature of therapy and what is expected.

The PQS items were examined with a factor analysis which detected three underlying factors, including one named Patient-Therapist Interaction which strongly predicted CALPAS scores. The items with the strongest factor loadings included those reflecting that the patient felt trusting, secure, and understood by the therapist, understood the therapist's comments, accepted the therapist's observations, and had clearly positive feelings toward the therapist.

Tobin (2006) identified patterns of positive and negative countertransference as reported by therapists using the Feeling Checklist immediately following a therapy session. These patterns of countertransference were found to appear in relation to specific therapeutic interactions, identified with the PQS, and suggested that therapists' countertransference feelings were determined primarily by how effective they believed they were in the session.

Heaton, Hill and Edwards (1995) took a novel approach, and examined the construct validity of the PQS with the Therapeutic Procedures Inventory (TPI; McNeilly \& Howard, 1989) and the Hill Counselor Verbal Response Category System (HCVRCS; Hill, 1978, 1985, 1992). Therapist techniques such as interpreting, paraphrasing, 
and giving directives were highly correlated between the PQS and TPI, which both assess process rated at the level of the entire therapy hour. Surprisingly, none of the clusters from the PQS were correlated with corresponding clusters on the HCVRCS, i.e., approval, directives, question, paraphrase, interpretation, confrontation, and self-disclosure. The authors speculated that the reason for these findings may be that the HVRCS measures process at the level of the individual sentence or speaking turn aggregated up to the session level (while the PQS captures process at the level of the entire therapy hour).

These findings highlight the importance of examining the PQS in relation to other measures of process (including those that take a more fine-grained look at treatment process at a micro-level), and suggest that much remains to be explored by combining measures.

\section{Innovations with the PQS}

Branching out from the lines of research reviewed above, more recent studies have applied the PQS to exciting new areas of investigation. Recognizing the need to expand process research into the area of child and adolescent psychotherapy, Schneider (2003) developed the Child Psychotherapy Q-Set (CPQ) by adapting the PQS for treatment with children, including play therapy, and is in the process of publishing an Adolescent Psychotherapy Q-set building on previous work by Bambery, Porcerelli and Ablon (2007, 2009).

Brent (2007) applied the original PQS to a sample of depressed adolescents receiving cognitive-behavioral treatment for inflammatory bowel disease. Replicating earlier findings, it was found that the treatment adhered most strongly to the CBT prototype; however, symptom improvement was strongly associated with processes from CBT, IPT, and dynamic therapy. Kelley et al. (2009) even used the PQS to study placebo effects in acupuncture treatment of irritable bowel syndrome. And Valter (1997) applied the PQS to a group treatment for 
latency-age girls with histories of sexual abuse, and used the PQS items to classify the self-object functions present in the group process.

As a final example of innovation, Pinto-Ferreira (2006) examined therapy process in the email communications between therapists and patients in 30 dyads. The email correspondence in each case complemented a low-frequency face to face therapy. Results showed that therapists' behaviors/communications were characterized by a clear, secure, and committed attitude. This commitment was seen in the patients' communications as well, and it was concluded that email correspondence can effectively be used to support traditional face to face treatment.

\section{Conclusions from 25 Years of Studying Process and Outcome of Psychotherapy using the PQS}

In conclusion, across many studies of psychotherapy process and outcome, researchers have successfully used the PQS to identify what processes influence treatment, how these processes change over time, and how they are associated with outcome. Here are some of the clinical and methodological lessons learned:

- Treatments of any kind are rarely theoretically pure and often include processes typically associated with other theoretical orientations. These borrowed processes need not be the most characteristic processes to play an important role in treatment outcome. Emotional exploration predicts positive outcomes across many different types of treatment. How clinicians help patients understand and regulate their emotions is critical to helping patients get better.

- Research using the PQS has also provided methodological clues for the future of psychotherapy research. You can't judge a book by its cover. Even in controlled trials, treatments are not pure. Thus, naturalistic studies have important value as a complement to RCTs. 
Studying therapist adherence is too simplistic since patients are coauthors of treatment process. Single-case studies provide an essential view of treatment not captured by aggregated data. The mysteries of psychotherapeutic change might best be understood by the intensive study of one treatment at a time since each dyad seems to create its own unique process associated with change.

The strengths of the PQS lie in its ability to capture therapy process in neutral, descriptive language that allows researchers from various theoretical orientations to communicate about the active ingredients in positive and negative outcomes of treatment. Extensive research with the PQS has begun to answer fundamental questions regarding psychotherapy about which many in our field have strong theory-driven hypotheses and opinions. It is our hope that the neutral language of the PQS will continue to inspire open-minded investigations across theoretical divides to answer increasingly complex questions about how all forms of psychotherapy work.

\section{References}

Ablon, J.S., \& Goodrich, C. (2004). Japanese Version.

Ablon, J.S., \& Jones, E.E. (1998). How expert clinicians' prototypes of an ideal treatment correlate with outcome in psychodynamic and cognitivebehavioral therapy. Psychotherapy Research, 8, 71-83.

Ablon, J.S., \& Jones, E.E. (1999). Psychotherapy process in the National Institute of Mental Health Treatment of Depression Collaborative Research Program. Journal of Consulting and Clinical Psychology, 67(1), 64-75.

Ablon, J.S., \& Jones, E.E. (2002). Validity of Controlled Clinical Trials of Psychotherapy: Findings from the NIMH Collaborative Study. The American Journal of Psychiatry, 159(5), 775-783.

Ablon, J.S., \& Jones, E.E. (2005). On analytic process. Journal of the American Psychoanalytic Association, 53, 541-568.

Ablon, J.S., Levy, R., \& Katzenstein, T. (2006). Beyond brand names of psychotherapy: Identifying empirically supported change processes. Psychotherapy: Theory, Research, Practice, Training, 43(2), 216-231.

Albani, C., Blaser, G., Jacobs, U., Jones, E.E., Thomä, H., \& Kächele, H. (2002). Amalia X's psychoanalytic therapy in the light of Jones's Psychotherapy Process Q-Sort. In M. Leuzinger-Bohleber \& M. Target (Eds.), 
Outcomes of Psychoanalytic Treatments. Perspectives for Therapists and Researchers (pp. 294-302). London/Philadelphia: Whurr Publishers.

Albani, C., Ablon, J.S., Levy, R.A., Mertens, W., \& Kachele, H. (2008). Der "Psychotherapie Prozess Q-Set" von Enrico E. Jones: Deutche Version (PQS-RD) und Anwendungen. Ulm, Germany: Verlag Ulmer Textbank.

Avila-Espada, Rampulla, Vidal \& Herrero (2008). Spanish version.

Bambery, M., Porcerelli, J.H., \& Ablon, J.S. (2007). Measuring psychotherapy process with the Adolescent Psychotherapy Q-set (APQ): Development and applications for training. Psychotherapy: Theory, Research, Practice, Training, 44(4), 405-422.

Bambery, M., Porcerelli, J.H., \& Ablon, J.S. (2009). Prototypes of psychodynamic and CBT psychotherapy with adolescents: Development and applications for training. Journal of the American Psychoanalytic Association, 57, $175-181$.

Castonguay, L.G., Goldfried, M.R., Wiser, S., Raue, P.J., \& Hayes, A.M. (1996). Predicting the effects of cognitive therapy for depression: A study of unique and common factors. Journal of Consulting and Clinical Psychology, 64, 497504.

Comninos and Greyer (2008). Rapid versus gradual responders.

Coombs, M.M., Coleman, D., \& Jones, E.E. (2002). Working with feelings: The importance of emotion in both cognitive-behavioral and interpersonal therapy in the NIMH Treatment of Depression Collaborative Research Program. Psychotherapy: Theory, Research, Practice, Training, 39(3), 233244.

Elkin, I., Shea, M.T., Watkins, J.T., Imber, S.D., Sotsky, S.M., Collins, J.F., Glass, D.R., Pilkonis, P.A., Leber, W.R., Docherty, J.P., Fiester, S.J., \& Parloff, M.B. (1989). National Institute of Mental Health treatment of depression collaborative research program: General effectiveness of treatments. Archives of General Psychiatry, 46, 971-982.

Fonagy, P., Target, M., Steele, H., \& Steele, M. (1998). Reflective-functioning manual, version 5, for application to Adult Attachment Interview. Unpublished Manuscript, University College London, United Kingdom.

Heaton, K.J., Hill, C.E., \& Edwards, L.A. (1995). Comparing molecular and molar methods of judging therapist techniques. Psychotherapy Research, 5(5), 141-153.

Henry, W.P., Strupp, H.H., Butler, S.F., Schacht, T.E., \& Binder, J.L. (1993). Effects of training in time-limited dynamic psychotherapy: Changes in therapist behavior. Journal of Consulting and Clinical Psychology, 61, 434440.

Hill, C.E. (1978). Development of a counselor verbal response category system. Journal of Counseling Psychology, 25, 461-468.

Hill, C.E. (1985). Manual for Counselor Verbal Response Modes Category System (Revised Version). Unpublished manuscript, University of Maryland at College Park.

Hill, C.C. (1992). An overview of four measures developed to test the Hill Process Model: Therapist intentions, therapist response modes, patient reactions, and client behaviors. Journal of Counseling and Development, 70, 728-739.

Jones, E.E. (1985). Manual for the Psychotherapy Process Q-Set. University of California at Berkeley, unpublished. 
Research in Psychotherapy 2011; 14(1): 14-48

http://www.researchinpsychotherapy.net

Jones, E.E. (2000). Therapeutic action: A guide to psychoanalytic therapy. Northvale, NJ: Aronson.

Jones, E.E., Cumming, J.D., \& Horowitz, M.J. (1988). Another look at the nonspecific hypothesis of therapeutic effectiveness. Journal of Consulting and Clinical Psychology, 56, 48-55.

Jones, E.E., Ghannam, J., Nigg, J.T., \& Dyer, J.F.P. (1993). A paradigm for single-case research: The time series study of a long term psychotherapy for depression. Journal of Consulting and Clinical Psychology, 61(3), 381-394.

Jones, E.E., Hall, S.A., \& Parke, L.A. (1991). The process of change: the Berkeley Psychotherapy Research Group. In L.E. Beutler \& M. Crago (Eds.), Psychotherapy Research: An International Review of Programmatic Studies (pp. 99-106). Washington: American Psychological Association.

Jones, E.E., Krupnick, J.H. \& Krieg, P.K. (1987). Some gender effects in a brief psychotherapy. Psychotherapy, 24, 336-352.

Jones, E.E., Parke, L.A. \& Pulos, S.M. (1992). How therapy is conducted in the private consulting room: A multivariate description of brief dynamic treatments. Psychotherapy Research, 2, 16-30.

Jones, E.E., \& Pulos, S.M. (1993). Comparing the process in psychodynamic and cognitive-behavioral therapies. Journal of Consulting and Clinical Psychology, 61(2), 306-316.

Jones, E.E., \& Windholz, M. (1990). The psychoanalytic case study: Toward a method for systematic inquiry. Journal of the American Psychoanalytic Association, 38(4), 985-1016.

Karlsson, R., \& Kermott, A. (2006). Reflective-functioning during the process in brief psychotherapies. Psychotherapy: Theory, Research, Practice, Training, 43(1) 65-84.

Katzenstein, T. (2007). Empirical validation of change processes in long-term psychodynamic psychotherapy: The bidirectional effects of clinician-patient interaction. Dissertation Abstracts International: Section B: The Sciences and Engineering, 67(8-B), pp. 4712.

Kelley, J.M., Lembo, A.J., Ablon, J.S., Villanueva, J.J., Conboy, L.A., Levy, R., Marci, C.D., Kerr, C.E., Kirsch, I., Jacobson, E.E., Riess, H., \& Kaptchuk, T.J. (2009). Patient and Practitioner Influences on the Placebo Effect in Irritable Bowel Syndrome. Psychosomatic Medicine, 71(7), 789-797.

Levy, R.A., Ablon, J.S., Ackerman, J.A., \& Seybert, C. (2008). The Psychotherapy Process Q-set and Amalia X, session 152. In C. Albani, J.S. Ablon, R.A. Levy, W. Mertens \& H. Kächele (Eds.), Der "Psychotherapie Prozess Q-Set" von Enrico E. Jones. Deutsche Version und Anwendungen (pp. 7-41). Ulm: Ulmer Textbank.

Marmar, C.R., Gaston, L., Gallagher, D., \& Thompson, L.W. (1989). Alliance and outcome in late-life depression. Journal of Nervous and Mental Disease, $177,464-472$.

McNeilly, D.L., \& Howard, K.L. (1991). The Therapeutic Procedures Inventory: Psychometric properties and relationship to phase of treatment. Journal of Psychotherapy Integration, 1, 223-235.

Pinto-Ferreira, C. (2005 or 2006). Wie funktioniert E-Mail-Therapie? Eine Einzelfallstudie mit dem "Psychotherapie Prozess Q-Sort (PQS)". PDP Psychodynamische Psychotherapie: Forum der tiefenpsychologisch fundierten Psychotherapie, 5(3), 171-177.

Pole, N., Ablon, J.S., \&, E. O’ Connor (2008). Using psychodynamic, cognitive behavioral, and control mastery prototypes to predict change: A new look at 
an old paradigm for long-term single-case research. Journal of Counseling Psychology, 55(2), 221-232.

Pole, N., Ablon, J.S., O'Connor, L., \& Weiss, J. (2002). Ideal Control mastery technique correlates with change in a single case. Psychotherapy: Theory, Research, Practice, Training, 39(1), 88-96.

Pole, N., \& Jones, E.E. (1998). The talking cure revisited: Content analyses of a two-year psychodynamic psychotherapy. Psychotherapy Research, 8(2), 171-189.

Porcerelli, J.H., Dauphin, V.B., Ablon, J.S., Leitman, S., \& Bambery, M. (2007). Psychoanalysis with avoidant personality disorder: A systematic case study. Psychotherapy: Theory, Research, Practice, Training, 44(1), 1-13.

Price, P.B., \& Jones, E.E. (1998). Examining the alliance using the Psychotherapy Process Q-Set. Psychotherapy: Theory, Research, Practice, Training, 35(3), 392-404.

Sandler, J. (1976). Countertransference and role-responsiveness. The International Journal of Psychoanalysis, 3(1), 43-47.

Schneider, C., \& Jones, E.E. (2003). The development of the child psychotherapy Q-set. Dissertation Abstracts International: Section B: The Sciences and Engineering, 65(2-B).

Serralta, F.B., Nunes, M.L.T., \& Ezirik, C.L. (2007). Development of a Portuguese version of the Psychotherapy Process Q-Set. Revista de Psiquiatria do Rio Grande do Sul, 29(1), 44-55. Available online from doi: 10.1590/S0101-81082007000100011.

Shedler, J., \& Westen, D. (1998). Refining the measure of Axis II: A Q-Sort procedure for assessing personality pathology. Assessment, 5, 333-353.

Sifneos, P.E., (1972). Short-term psychotherapy and emotional crisis. Cambridge: Harvard University Press.

Spence, D.P., Dahl, H., \& Jones, E.E. (1993). The impact of interpretation on associative freedom. Journal of Consulting and Clinical Psychology, 61(3), 395-402.

Tobin, M.J. (2006). Countertransference and therapeutic interaction: An exploratory study. Dissertation Abstracts International: Section B: The Sciences and Engineering, 67(4-B), pp. 2247.

Valter, M.W. (1997). Identification of selfobject functions in group process: A Q-Sort method. Dissertation Abstracts International: Section B: The Sciences and Engineering, 57(7-B), pp. 4730.

Wallerstein, R. (1986). Forty-two lives in treatment: A study of psychoanalysis and psychotherapy. New York: Guilford Press. 